need for the latest available evidence to improve our nursing protocols and (b) the availability of suitable graduation subjects in this instrument.

\section{PO-0893 WHAT DO THE MOTHERS' PREFER FOR MATERIALS ABOUT CHILDREN'S CARE?: CLOTHING, HYGENIC CARE AND NUTRITION}

${ }^{1} \mathrm{M}$ Uzun, ${ }^{2} \mathrm{NY}$ Atar, ${ }^{3} \mathrm{M}$ Kar, ${ }^{3} \mathrm{~F}$ Yilmaz, ${ }^{3} \mathrm{C}$ Karasakal. ${ }^{1}$ Child Health and IIInesses Nursing, Bulent Ecevit University, Zonguldak, Turkey; ${ }^{2}$ Essentials of Nursing, Bulent Ecevit University, Zonguldak, Turkey; ${ }^{3}$ Nursing Department, Bulent Ecevit University, Zonguldak, Turkey

\subsection{6/archdischild-2014-307384.1515}

Background and aims Immature organ systems of children are often less capable of fending off chemical assaults. Subtle damage to developing bodies may lead to disease later in life. Mothers need to have a careful consideration. As fragile living being children need to be carefully protected and need proper clothing, hygenic care and healty nutrition. The aim of this study was detemining preference of mothers' about cloths, hygenic materials (especially tolietries) and nutrition for their children.

Methods A descriptive quantitative approach was used in study. The data were obtained from 198 mothers who has child in different ages by a questionnaire designed by researchers. Data was evaluated using the descriptive statistics available in the Statistical Package for Social Sciences Software (SPSS 16.0).

Results Most of the mothers were $(43,4 \%)$ between 26-30, high-school graduate $(\% 34,3)$ and housewife $(66,2 \%)$, the salary of (45,5\%) 1001-1500 TL. The mother's selection criteria for their children's clothes, hygienic materials, shoes and food are; for clothes according to texture (cotton) (50,8\%), for hygienic material according to be hypoallergic (50,3\%), for shoes according to flexibility $(39,1 \%)$, for food according to experience (66\%).

Conclusion It is shown that the mothers' preference were focus on the best things they can effort. The age, economical status and job didn't influence their decision directly.

\section{PO-0894 MY HANDS CLEAN, I AM HEALTHY}

${ }^{1} \mathrm{M}$ Uzun, ${ }^{2} \mathrm{~A}$ Gündogdu, ${ }^{3} \mathrm{~F}$ Yilmaz, ${ }^{3} \mathrm{M}$ Kar, ${ }^{3} \mathrm{C}$ Karasakal. ${ }^{1} \mathrm{Child}$ Health and IIInesses Nursing, Bulent Ecevit University, Zonguldak, Turkey; ${ }^{2}$ Nursing, Eregli Educational and Research Hospital, Zonguldak, Turkey; ${ }^{3}$ Nursing, Bulent Ecevit University Zonguldak School of Health, Zonguldak, Turkey

\subsection{6/archdischild-2014-307384.1516}

Background and aims Hygen education is one of the most important self-care activity in pre-school children. We can protect the chilrens from mycrobic diseases by teaching the principles of hand hygene, toilet hygene and bathing. The purpose of the study is teaching true techniques of hand washing, rules of toilet and bathing hygene to pre-school children.

Methods This study performed with 150 pre-school children between the age of 3-6 during the Child Health and Illnesses Nursing Course. Four nursing students prepared a powerpoint presentation about microbes, preventions, hand, bathing, toilet hygene by the help of their lecturer. They presented powerpoint presentation to the pre-school students, next showed videos about hand, toilet and bath hygene, learnt true hand washing technique by demonstration.
Results Although benefits of hygene and harm of microbes learning ability of children changed according to the age most of the students achieved the goals of the studies. $90 \%$ of 4 years of students washed their hands in true technique, $80 \%$ of 5 years old students obeyed hygyene rules for toilet and bathing and $73 \%$ of 6 years old students count the benefits of hygene and harm of microbes.

Conclusion The learning activities of children can be supported by explanation, demostration and application. Nursing students can perform great role on teaching the subjects regarding protection and promoting of health. If the student see the true role model behind them, they can learn true activity easily.

\section{P0-0894a THE EFFICACY OF MECHANICAL VIBRATION OF HEEL STICK PAIN IN TERM NEONATES}

${ }^{1} \mathrm{FN}$ Dolu, ${ }^{2} \mathrm{~A}$ Karakoc, ${ }^{1}$ I Mungan Akin. ${ }^{1}$ Department of Pediatrics, Istanbul Medeniyet University Goztepe Education and Research Hospital, Istanbul, Turkey: ${ }^{2}$ Department of Pediatric Nursery, Marmara University Institute of Health Sciences, Istanbul, Turkey

\subsection{6/archdischild-2014-307384.1517}

Background and aims During 80's most paediatricians believed that newborns do not feel pain because of immature peripheral nervous system and incomplete myelinization; which turned out to be false. Today, either non-pharmacologic or pharmacological analgesia during invasive procedures is mandatory. On the other hand vibration is very well known for pain relief since 40 's. In this study we aimed to evaluate the effectiveness of mechanical vibration application to avoid pain sensation during heel puncture in newborn babies.

Methods This study is a prospective single centre, randomised clinical trial. Sixty healthy term neonates were divided into 2 for Control (sucrose) and Study groups (sucrose+vibration). Heel puncture was applied to these babies for the 1st time during routine testing for metabolic disease screening. Data of the participants were recorded and NIPS was used to evaluate the behavioural response of neonates during pain.

Results Cronbach's alpha coefficient for NIPS scoring system was found as 0.85 during procedure and as 0.87 after procedure. Reliability of the study was found to be high. Mean of NIPS scores in study and control groups were significantly higher during procedure and after procedure $(\mathrm{p}<0.001)$.

Conclusions Mechanical vibration is found to be effective in decreasing pain sensation in neonates and can be applied as one of non-pharmacologic methods.

\section{Nursing-Neonatal Others}

\section{PO-0895 RURAL RESEARCH REVIVED}

${ }^{1}$ BJ Bromage, ${ }^{2} \mathrm{~L}$ Trembath, ${ }^{1} \mathrm{PF}$ Munyard, 'AC Collinson. ${ }^{1}$ Neonatal Unit, Royal Cornwall Hospital, Truro, UK; ${ }^{2}$ Research Development and Innovation, Royal Cornwall Hospital, Truro, UK

\subsection{6/archdischild-2014-307384.1518}

Background and aims Our remote Local Neonatal Unit (LNNU) is located in Cornwall, and is 180 miles from the nearest tertiary centre. We already had research experience, but the lack of dedicated nurse support was inhibiting further research participation. Our aim was to promote neonatal research to facilitate inclusion in more studies. 